\title{
Electrochemical Characteristics of Sn Film Prepared \\ by Pulse Electrodeposition Method as Negative Electrode for Lithium Secondary Batteries
}

\author{
Koichi UI ${ }^{a}{ }^{*}$, Shinei KIKUCHI ${ }^{a}$,Yoshihiro KADOMA ${ }^{a}$, Naoaki KUMAGAI ${ }^{\text {a }}$, \\ and Shigeru ITO ${ }^{b}$
}

${ }^{a}$ Department of Frontier Materials and Functional Engineering, Graduate School of Engineering, Iwate University, Morioka, Iwate 020-8551, Japan.

${ }^{b}$ Faculty of Science and Technology, Tokyo University of Science, Noda, Chiba 278-8510, Japan

- Article type

- *orresponding author

- Business Affiliation

- Full postal address

- Phone and fax number

- E-mail address

\section{IMLB 2008 Special Issue}

Associate Professor Koichi UI (M)

Iwate University

4-3-5 Ueda, Morioka, Iwate 020-8551, Japan

$+81-19-621-6340 / 6314$

kui@,iwate-u.ac.jp 


\begin{abstract}
In order to improve the cyclability of Sn negative electrode, we tried preparing the Sn film negative electrode by a pulse electrodeposition. Based on the SEM observations, the crystal grains of the Sn film after the pulse electrodeposition were comparatively homogeneous and their grain size was ca. $1 \mu \mathrm{m}$. The discharge capacity and the charge-discharge efficiency at the 1 st cycle were $679.3 \mathrm{mAh} \mathrm{g}^{-1}$ and $93.0 \%$, respectively. The charge-discharge tests indicated that the initial electrochemical characteristic of Sn film electrode prepared by a pulse electrodeposition was much better than that of the Sn film electrode prepared by a constant current electrodeposition. The GD-OES profile suggested that $\mathrm{Li}^{+}$ions were easily extracted during the discharge reaction. In addition, it was found that no exfoliation of the film was observed after the 1st discharge though the cracking in the film was observed after the 1st discharge. Consequently, the Sn film electrode prepared by a pulse electrodeposition exhibited a better cyclability for the initial 10 cycles compared to the Sn film electrode prepared by a constant current electrodeposition. By reducing the particle size and repressing the morphological change, the initial electrochemical characteristics were considerably improved. (193 words)
\end{abstract}

Keywords: Lithium secondary battery, Negative electrode, Tin, Pulse electrodeposition, GD-OES 


\section{Introduction}

Lithium ion secondary batteries have the highest energy density in commercialized batteries. The demand for lithium ion secondary batteries as a high-power source has been steadily increasing due to the advancement of portable electronic devices. It is thought that this is due to the development of novel materials. Graphite is mainly used as negative electrode materials for lithium ion secondary batteries and yields a theoretical capacity of $372 \mathrm{mAh} \mathrm{g}^{-1}$. In contrast, Sn yields a higher theoretical capacity of $994 \mathrm{mAh} \mathrm{g}^{-1}$, which is equivalent to about 2.5 times of the capacity of graphite [1]. However, one major problem is that the cyclability of the Sn electrode is poor [2-4]. During the charge-discharge reaction process, the volume change is caused by the $\mathrm{Li}^{+}$ion insertion/extraction into/from $\mathrm{Sn}$. Such a morphological change results in cracking and crumbling of the electrode with the concomitant loss of electrical contact between inter-particles, and the particles and the current collector, resulting in poor cycling performance. In order to solve these problems, synthesizing nanosized active materials $[5,6]$, preparing the film electrode by electrodeposition [7], and preparing binary alloys, such as the Sn-M alloy $(\mathrm{M}=\mathrm{Ti}, \mathrm{V}, \mathrm{Cr}$, $\mathrm{Mn}, \mathrm{Fe}, \mathrm{Co}, \mathrm{Ni}, \mathrm{Cu}$ etc.) [8-27], have been reported.

The most effective way of improving the cyclability of Sn-based electrodes may be to synthesize small-sized Sn particles. As an example of the preparation of Sn nanoparticles, Caballero et al. reported that $\mathrm{Sn}$ nanoparticles were synthesized in the presence of cellulose fibers and the discharge capacity was maintained above $500 \mathrm{Ah} \mathrm{kg}^{-1}$ after 40 cycles [6]. On the other hand, electrodeposited Sn-based alloy thin films [7, 8, 10-17, 21, 25-27] were widely evaluated with the view to overcoming the above problems during the charge-discharge reaction. The electrodepositing method is simpler than the currently-used 
powder preparation method because there is no need for any binder or conductive additives. The discharge capacity of the electrodeposited $\mathrm{Sn}$ film electrode on a smooth $\mathrm{Cu}$ substrate was ca. $650 \mathrm{mAh} \mathrm{g}^{-1}\left(1 \mathrm{st}\right.$ cycle) and ca. $200 \mathrm{mAhg}^{-1}(20 \mathrm{th}$ cycle) [21]. Therefore, the cyclability of Sn-based electrodes may be improved by adopting and combining both advantages.

In this study, in order to improve the electrochemical characteristics of a Sn negative electrode, we tried preparing the $\mathrm{Sn}$ film negative electrode by a pulse electrodeposition method, which is effective for improving the adhesion strength between the active material and substrate, and suitable for producing microcrystal grains of the active material particles. At the same time, the electrochemical characteristics, such as the cyclability of the Sn film electrode, were evaluated. The main purpose of this report is to investigate and understand the superiority of the Sn film electrode prepared by a constant current pulse electrodeposition method (pulse method), in comparison with that prepared using a conventional constant current electrodeposition method (constant current method).

\section{Experimental}

The electrodeposition bath listed in Table I was prepared using $\mathrm{SnSO}_{4}$ (Wako Pure Chemical Industries, Ltd., 96\%), gelatin, and sulfuric acid. The Sn film was electrodeposited on one side of the $\mathrm{Ni}$ foil (Nilaco Co., 99.9\%, $0.15 \mathrm{~mm}$ thickness) in the bath by pulse electrodeposition. The conditions of the pulse method were as follows; a bath temperature of $50{ }^{\circ} \mathrm{C}$, a current density of $76 \mathrm{~mA} \mathrm{~cm}^{-2}$, a pulse period of $5 \mathrm{~s}$, a pulse of duty ratio 0.2 , and a deposition time of $2.0 \mathrm{~min}$. For comparison, the $\mathrm{Sn}$ film was similarly 
electrodeposited on one side of the $\mathrm{Ni}$ foil in the bath by constant current electrodeposition. The conditions of the constant current method were as follows; a bath temperature of $50{ }^{\circ} \mathrm{C}$, a current density of $50 \mathrm{~mA} \mathrm{~cm}$, and a deposition time of $1.0 \mathrm{~min}$. The pulse current was controlled using a computer-controlled electrochemical measuring system (Hokuto Denko, HZ-3000). The electricity was set at $1.8 \mathrm{C} \mathrm{cm}^{-2}$ for the pulse electrodeposition and $3.0 \mathrm{C}$ $\mathrm{cm}^{-2}$ for the constant current electrodeposition. The crystal structure and surface morphology of the electrodeposited films were examined by X-ray diffraction (XRD) using an X-ray diffractometer (Rigaku Denki, RINT2200, AFC7) with $\mathrm{Cu}-\mathrm{K} \alpha$ radiation $(\lambda=$ $0.15418 \mathrm{~nm}$ ) and scanning electron microscopy (Hitachi, N-2250NII, SEM).

The three-electrode cell, which consisted of the electrodeposited Sn film electrode (W.E.), a Li foil (R.E. and C.E.), and a $1.0 \mathrm{~mol} \mathrm{dm}{ }^{-3}$ (M) solution of $\mathrm{LiClO}_{4}$ in $\mathrm{EC}$ : DEC (50 : 50 vol.\%) (Mitsubishi Chemical Co.; water content under $30 \mathrm{ppm}$ ), was used for the electrochemical measurements. The cells were assembled in a glove box (Miwa Mfg Co., Ltd., DBO-1NKP-1U-2) filled with dry argon at room temperature. Cyclic voltammetry (CV) was performed using a computer-controlled electrochemical measuring system (Hokuto Denko, HZ-3000). The cyclic voltammograms were measured at the scan rate of $0.1 \mathrm{mV} \mathrm{s}^{-1}$ between the potential of 0.02 and $2.00 \mathrm{~V}\left(v s . \mathrm{Li} / \mathrm{Li}^{+}\right)$. The charge-discharge cycle tests (the cathodic polarization due to $\mathrm{Li}^{+}$ion insertion into the $\mathrm{Sn}$ film is defined as the charge and the anodic polarization due to $\mathrm{Li}^{+}$ion extraction from that is defined as the discharge.) were performed using an automatic battery charging-discharging instrument (Hokuto Denko, HJR-1010mSM8) at a current density of $198 \mathrm{mAg}^{-1}$ (0.2 C rate) between 0.02 and $1.50 \mathrm{~V}$. For the ex situ SEM observations and the ex situ XRD measurements of 
the Sn film electrodes, the electrode was charged or discharged at a constant current of 198 $\mathrm{mA} \mathrm{g}^{-1}$ to the $0.02 \mathrm{~V}$ or $1.50 \mathrm{~V}$ and remained at that potential for $12 \mathrm{~h}$. The cells were then disassembled in the glove box to obtain the sample electrode. The obtained electrodes were then washed with DEC (Wako Chemical Industries, Ltd., superfine quality). In the case of the ex situ SEM observations, the electrode was dried in the glove box. For the ex situ XRD measurements, the electrodes were sealed in a propylene film (Rigaku Denki, Cell sheet) to prevent contact of the sample with air. The depth profile of the elements in the Sn film containing Li after being charged and discharged was determined by glow discharge plasmas-optical emission spectroscopy (HORIBA, JY-5000RF, GD-OES) after the test specimens were successively washed with DEC.

\section{Results and discussion}

The amount of the electrodeposited film was about $1.0 \mathrm{mg} \mathrm{cm}^{-2}$. We analyzed the crystalline phase of the film by X-ray diffraction (Fig. 1). For comparison, Fig. 1 also shows the X-ray diffraction pattern of the film prepared by constant current method. The ex situ XRD results indicate that the most of the peaks were assigned to metallic Sn regardless of the electrodeposition method. The weak peak $(\square)$, which was not indexed to metallic $\mathrm{Sn}$, was observed at around $28^{\circ}$. This peak is seemed to be due to $\mathrm{SnO}$, so that a small amount of $\mathrm{SnO}$ may exist on the surface of the metallic $\mathrm{Sn}$.

The CVs were measured in order to investigate the electrochemical redox behavior

of the Sn film electrodes (Fig. 2). For the Sn film electrode prepared by the constant current electrodeposition (Fig. 2(a)), the coupled redox peaks were clearly observed in the potential 
range from 0 to $1.0 \mathrm{~V}$. The reduction and oxidation currents corresponding to the insertion and extraction reactions of the $\mathrm{Li}^{+}$ion into and from the $\mathrm{Sn}$ film electrode were observed in the potential range from 0 to $0.8 \mathrm{~V}$ and from 0.35 to $1.0 \mathrm{~V}$, respectively. A small reduction peak was observed at about $1.6 \mathrm{~V}$. This peak may be due to the decomposition of the electrolyte or the reduction of $\mathrm{SnO}$ [2-4]. In addition, the redox currents during the 2 nd cycle slightly decreased. In contrast, the 1 st behavior of the Sn film electrode prepared by using the pulse method was almost similar to that of the $\mathrm{Sn}$ film electrode prepared by the constant current method (Fig. 2(b)). In the case of the pulse method, however, the redox currents during the 2 nd cycle did not decrease very much. Based on these results, it was found that the cyclability of the Sn film electrode prepared by the pulse method might be better.

The charge-discharge cycle tests of the Sn film electrode were next carried out. Fig. 3 indicates the charge-discharge curves at a current density of $198 \mathrm{~mA} \mathrm{~g}^{-1}$ (0.2C). As seen in Fig. 3(a), for the $\mathrm{Sn}$ film electrode prepared by the constant current method, the discharge capacity and the charge-discharge efficiency at the 1 st cycle were $738.6 \mathrm{mAh} \mathrm{g}^{-1}$ and $88.1 \%$, respectively. The cycle performance was not stable after the 2 nd cycle as the discharge capacity and charge-discharge efficiency for the 2 nd cycle dramatically decreased to $230.3 \mathrm{mAh} \mathrm{g}^{-1}$ and $69.3 \%$, respectively. It is considered that the capacity decreased due to cracking or exfoliation of the film. In contrast, the 1st charge-discharge curve profile of the Sn film electrode prepared by the pulse method was very similar to that of the Sn film electrode prepared by using the constant current method (Fig. 3(b)). The discharge capacity and the charge-discharge efficiency at the 1 st cycle were $679.3 \mathrm{mAh} \mathrm{g}^{-1}$ and $93.0 \%$, respectively. The cycle performance was quite stable after the 2 nd cycle because the 
discharge capacity and charge-discharge efficiency for the 2nd cycle were $693.2 \mathrm{mAh} \mathrm{g}^{-1}$ and $102 \%$, respectively. The capacity of the Sn film electrode prepared by the pulse method did not decrease very much. Moreover, it is found that the 1st charge-discharge efficiency of the Sn film electrode prepared by the pulse method was higher than that of the Sn film electrode prepared by the constant current method.

In order to thoroughly investigate the influence of the morphological change on the electrochemical characteristic, the surface of the films was observed by SEM. As shown in Fig. 4(a), the crystal grain size of the Sn film prepared by the constant current method was ca. $1 \sim 4 \mu \mathrm{m}$. The expansion of particles and the cracking in some particles were observed after the 1st charging (Fig. 4(b)). Exfoliation of the Sn film was observed all over the current collector after the 1st discharging (Fig. 4(c)). This would be regarded as the main cause of the capacity decrease. In contrast, the crystal grains of the $\mathrm{Sn}$ film by the pulse method were comparatively homogeneous and the grain size was considerably small $c a .1$ $\mu \mathrm{m}$ (Fig. 4(d)). It was found that the microcrystal grains of active material particles were obtained by the pulse method. The expansion of the particles was similarly observed, but cracking of the particle was not generated after the 1st charging (Fig. 4(e)). The cracking in the Sn film was observed after the 1st discharging (Fig. 4(f)). However, it was found that the morphology of the particles was mostly maintained and the most of the film was only slightly exfoliated from the current collector. Tamura et al. reported that the cycle performance of the 79.8Sn-20.2Co alloy film electrode was excellent for 20th cycles though the cracking in the film appeared after the 1st charge-discharge reactions [19], suggesting that the cycle performance may not decrease because of the cracking formation. 
Based on these results, it is considered that the stress in the film during the charge-discharge reaction was relaxed and the exfoliation of the film was restrained by reducing the particle size and forming the homogenous particle.

Furthermore, in order to investigate the reason for the initial efficiency loss, the depth profiles of $\mathrm{Li}$ in the $\mathrm{Sn}$ films after the 1st charge-discharge tests were measured by GD-OES. We could obtain beneficial information concerning the depth profile of Li in the Al film after the 1st charge-discharge reactions by GD-OES [28, 29]. Fig. 5 shows the GD-OES analysis of the as-deposited Sn film electrodes before/after 1st charge and after the 1st discharge. As for the fresh films, most of Sn existed near the surface of the film, while the amount of Sn gradually decreased with increasing the sputtering time (Figs. 5(a) and (d)). Figs. 5(b) and (e) show the GD-OES analysis of the Sn film electrodes after the 1st charge. The intensity of the Li was higher than that of the $\mathrm{Sn}$ in the total $\mathrm{Sn}$ film, indicating that Li diffused into the Sn particle. Moreover, the intensity of carbon was only slightly detected in the Sn films and near the surface. Therefore, the initial efficiency loss would not be due to the decomposition of the electrolyte. From the GD-OES analysis of the Sn film electrodes after the 1st discharge (Figs. 5(c) and (f)), it was found that Li was extracted from the Sn films because the Li intensity totally decreased after the 1st discharge. However, all the Li was not extracted from the Sn films during discharge, and a part of the Li remained in the Sn films especially near the surface of the films after the 1st discharge. Moreover, a significant difference in Figs. 5(c) and (f) was observed. In the case of the Sn film electrode prepared by the constant current method, the intensity of the Li was much higher than that of the Sn in the total Sn film (Fig. 5(c)), whereas for the Sn film electrode prepared by the pulse method, that of the Li was lower than that of the $\mathrm{Sn}$ in the total $\mathrm{Sn}$ 
film (Fig. 5(f)). From these results, it was found that the charge-discharge efficiency of the Sn film electrode prepared by the pulse method was higher than that of the Sn film electrode prepared by the constant current method. It is considered that the extraction of $\mathrm{Li}$ during the discharge reaction was easier in the pulse electrodeposition film because the diffusion length of Li was shortened and the reaction surface area was increased by reducing the particle size $[5,6]$. Based on these results, it was suggested that the $\mathrm{Li}$ remaining in the Sn film was the main reason for the initial efficiency loss especially for the constant current method because only a slight amount of $\mathrm{SnO}$ was present.

Fig. 6(a) shows the cycle performance of the Sn film electrode prepared by the constant current method. The discharge capacity rapidly faded at the 2 nd cycle. The rapid decrease seems to be due to the exfoliation of the Sn films during the 1st discharge. In contrast, the Sn film electrode prepared by the pulse method exhibited a better cyclability for the first 10 cycles compared to the Sn film electrode prepared by the constant current method (Fig. 6(b)), although a gradual capacity fade occurred over 20 cycles and the charge-discharge efficiency of the Sn film electrode prepared by the pulse method was slightly lower than that of the Sn film electrode prepared by the constant current method after the 11th cycle. This result indicates that the exfoliation of the film could not be sufficiently suppressed only by reducing the crystal grain size.

Based on these results, it was found that the electrodeposition method and morphological change in the Sn film with charge and discharge have an influence on the initial electrochemical characteristics, and the initial cycle performance of the Sn film electrode was considerably improved by the pulse method. 


\section{Conclusion}

To improve the electrochemical characteristics of the Sn negative electrode, we have prepared the Sn film electrode by a pulse electrodeposition and obtained the following results in comparison with the $\mathrm{Sn}$ film electrode prepared by a constant current electrodeposition. The crystal grains of the $\mathrm{Sn}$ film from the pulse method were comparatively homogeneous and the size was $c a .1 \mu \mathrm{m}$. The initial cycle performance of the Sn film prepared by the pulse method was superior to that of the $\mathrm{Sn}$ film prepared by the constant current method. This phenomenon mainly attributes to the serious exfoliation of the Sn film prepared by the constant current method. In addition, it is noteworthy that the 1st charge-discharge efficiency of the $\mathrm{Sn}$ film electrode from the pulse method was higher than that of the Sn film electrode from the constant current method. The GD-OES analysis suggests that the extraction of $\mathrm{Li}^{+}$ions during the discharge reaction occurred easily. By reducing the particle size and increasing the reaction surface area, the initial electrochemical characteristics were considerably improved.

We may reasonably conclude that the $\mathrm{Sn}$ film prepared by the pulse method showed a considerable improvement in the initial cycle performance, but, further improvement of the electrochemical characteristic will be needed. We will show strategies to solve the problem in the following paper in this series.

\section{Acknowledgement}

We thank Mr. N. Asoh and Y. Anbe for the GD-OES measurements and their helpful discussions. 


\section{References}

[1] M. Winter and J. O. Besenhard, Electrochim. Acta, 45 (1999) 31.

[2] I. A. Courtney and J. R. Dahn, J. Electrochem. Soc., 144 (1997) 2045.

[3] L. Y. Beaulieu, S. D. Beattie, T. D. Hatchard, and J. R. Dahn, J. Electrochem. Soc., 150 (2003) A419.

[4] A. Sivashanmugam, T. P. Kumar, N.G. Renganathan, S. Gopukumar, M. Wohlfahrt-Mehrens, and J. Garche, J. Power Sources, 144 (2005) 197.

[5] H. Li, G. Zhu, X. Huang, and L. Chen, J. Mater. Chem., 10 (2000) 693.

[6] Á. Caballero, J. Morales, and L. Sánchez, Electrochem. Solid-State Lett., 8 (2005) A464.

[7] H. Morimoto, S. Tobishima, and H. Negishi, J. Power Sources, 146 (2005) 469.

[8] O. Mao, R. A. Dunlap, and J. R. Dahn, J. Electrochem. Soc., 146 (1999) 405.

[9] L.Y. Beaulieu and J. R. Dahn, J. Electrochem. Soc., 147 (2000) 3237.

[10] N. Tamura, R. Ohshita, M. Fujimoto, S. Fujitani, M. Kamino, and I. Yonezu, J. Power Sources, 107 (2002) 48.

[11] H. Mukaibo, T. Sumi, T. Yokoshima, T. Momma, and T. Osaka, Electrochem. Solid-State Lett., 6 (2003) A218.

[12] N. Tamura, R. Ohshita, M. Fujimoto, M. Kamino, and S. Fujitani, J. Electrochem. Soc., 150 (2003) A679.

[13] T. Sonoda and T. Sakai, J. Surf. Finish. Soc. Jpn., 54 (2003) 492.

[14] S. D. Beattie and J. R. Dahn, J. Electrochem. Soc., 150 (2003) A894.

[15] N. Tamura, M. Fujimoto, M. Kamino, and S. Fujitani, Electrochim. Acta, 49 (2004) 
1949.

[16] H. Mukaibo, T. Momma, M. Mohamedi, and T. Osaka, J. Electrochem. Soc., 152 (2005) A560.

[17] H. Mukaibo, T. Momma, and T. Osaka, J. Power Sources, 146 (2005) 457.

[18] H. Yoshinaga, J. Asai, M. Wada, K. Yamamoto, and T. Sakai, Electrochemistry, 73, (2005) 897 .

[19] J. Zhang and Y. Xia, J. Electrochem. Soc., 153 (2006) A1466.

[20] N. Tamura, Y. Kato, A. Mikami, M. Kamino, S. Matsuta, and S. Fujitani, J. Electrochem. Soc., 153 (2006) A1626.

[21] J. W. Park, S. Rajendran, and H. Kwon, J. Power Sources, 159 (2006) 1409.

[22] A. D. W. Todd, R. E. Mar, and J. R. Dahn, J. Electrochem. Soc., 153 (2006) A1998.

[23] N. Tamura, Y. Kato, A. Mikami, M. Kamino, S. Matsuta, and S. Fujitani, J. Electrochem. Soc., 153 (2006) A2227.

[24] A. D. W. Todd, R. E. Mar, and J. R. Dahn, J. Electrochem. Soc., 154 (2007) A597.

[25] F. S. Ke, L. Huang, H. B. Wei, J. S. Cai, X. Y. Fan, F. Z. Yang, and S. G. Sun, J. Power Sources, 170 (2007) 450.

[26] F. S. Ke, L. Huang, J. S. Cai, and S. G. Sun, Electrochim. Acta, 52 (2007) 6741.

[27] H. Zhao, C. Jiang, X. He, J. Ren, and C. Wan, Electrochim. Acta, 52 (2007) 7820.

[28] K. Ui, T. Minami, K. Ishikawa, Y. Idemoto, and N. Koura, Electrochemistry, 73 (2005) 279.

[29] K. Ui, K. Yamamoto, K. Ishikawa, T. Minami, K. Takeuchi, M. Itagaki, K. Watanabe, and N. Koura, J. Power Sources, 183, (2008) 724. 


\section{All figure captions}

Fig. 1. XRD patterns of Sn films prepared by (a) constant current electrodeposition method, and (b) constant current pulse deposition method. $(\bigcirc) \mathrm{Ni} ;(\nabla) \mathrm{Sn} ;(\square) \mathrm{SnO}$.

Fig. 2. Cyclic voltammograms of Sn film electrodes prepared by (a) constant current electrodeposition method, and (b) constant current pulse electrodeposition method. Potential range: $0.02-2.00 \mathrm{~V}$ vs. $\mathrm{Li}_{1} / \mathrm{Li}^{+}$, scan rate $: 0.1 \mathrm{mV} \mathrm{s}^{-1} ;($ — ) 1 st cycle ; ( - _....... ) 2nd cycle.

Fig. 3. Charge-discharge curves of Sn film electrodes prepared by (a) constant current electrodeposition method and (b) constant current pulse electrodeposition method. Potential range: $0.02-1.50 \mathrm{~V}$ vs. $\mathrm{Li}^{2} / \mathrm{Li}^{+}$, C. D. : $198 \mathrm{~mA} \mathrm{~g}{ }^{-1}(0.2 \mathrm{C}) ;($ ) 1 st cycle ; ( - - - 2nd cycle.

Fig. 4. SEM images of Sn film electrodes as-deposited (upper), after 1st charging (middle), and after 1st discharging (bottom). The Sn film electrodes prepared by the constant current electrodeposition method $(\mathrm{a}, \mathrm{b}, \mathrm{c})$ and the constant current pulse electrodeposition method $(d, e, f)$.

Fig. 5. GD-OES analysis of the Sn film electrodes as deposited (upper), after 1st charging (middle), and after 1st discharging (bottom). The Sn film electrodes prepared by the constant current electrodeposition method (a, b, c), and the constant current pulse electrodeposition method (d, e, f).

Fig. 6. Cycle performance and charge-discharge efficiency of Sn film electrodes prepared by (a) constant current electrodeposition method, and (b) constant current pulse 
electrodeposition method. Potential range : 0.02 - $1.50 \mathrm{~V}$ vs. $\mathrm{Li} / \mathrm{Li}^{+}, \mathrm{C}$. D. : $198 \mathrm{~mA} \mathrm{~g} \mathrm{~g}^{-1}$ $(0.2 \mathrm{C})$.

Table 1 Composition of the electrodeposition bath for Sn film. 


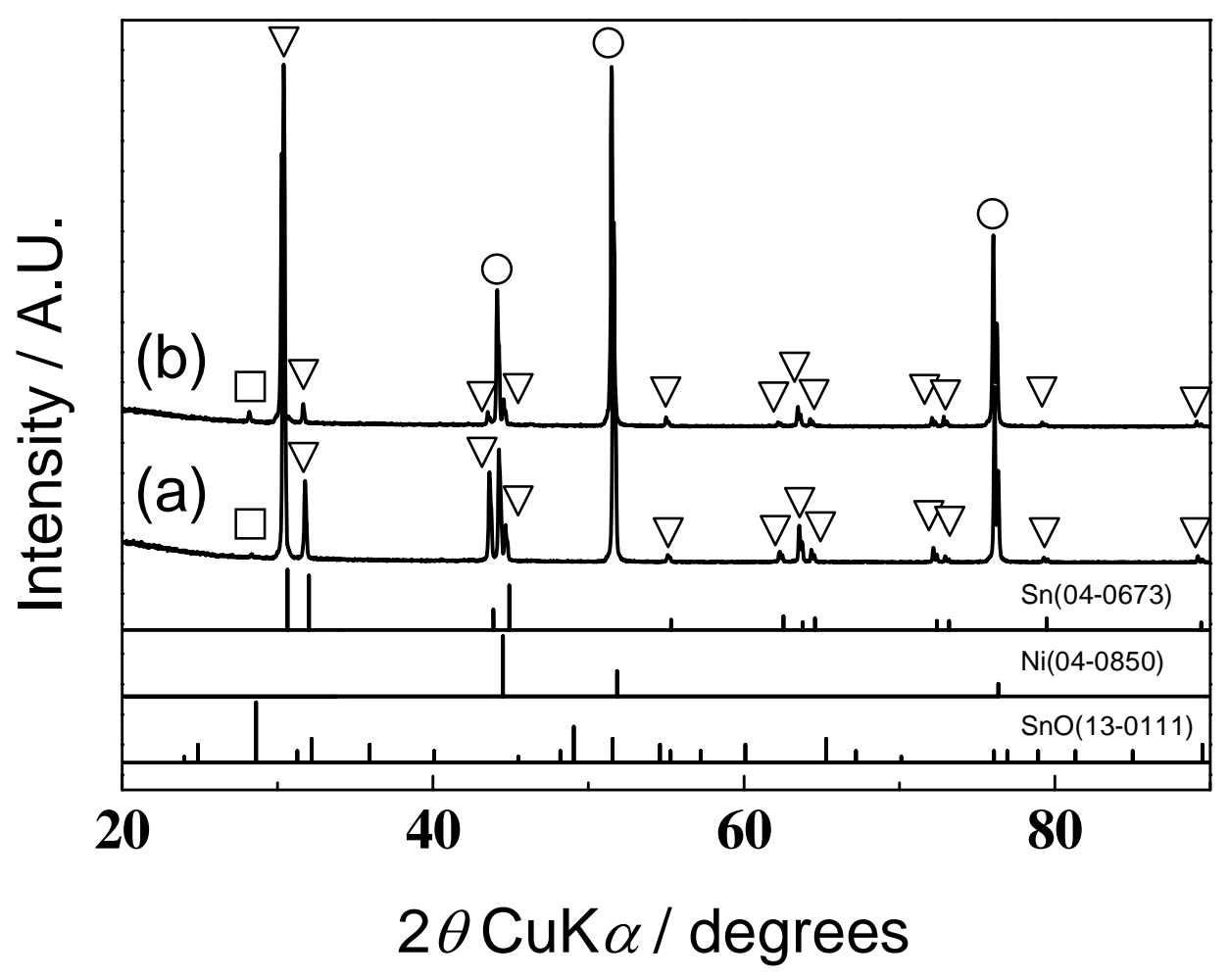

Fig. 1. 

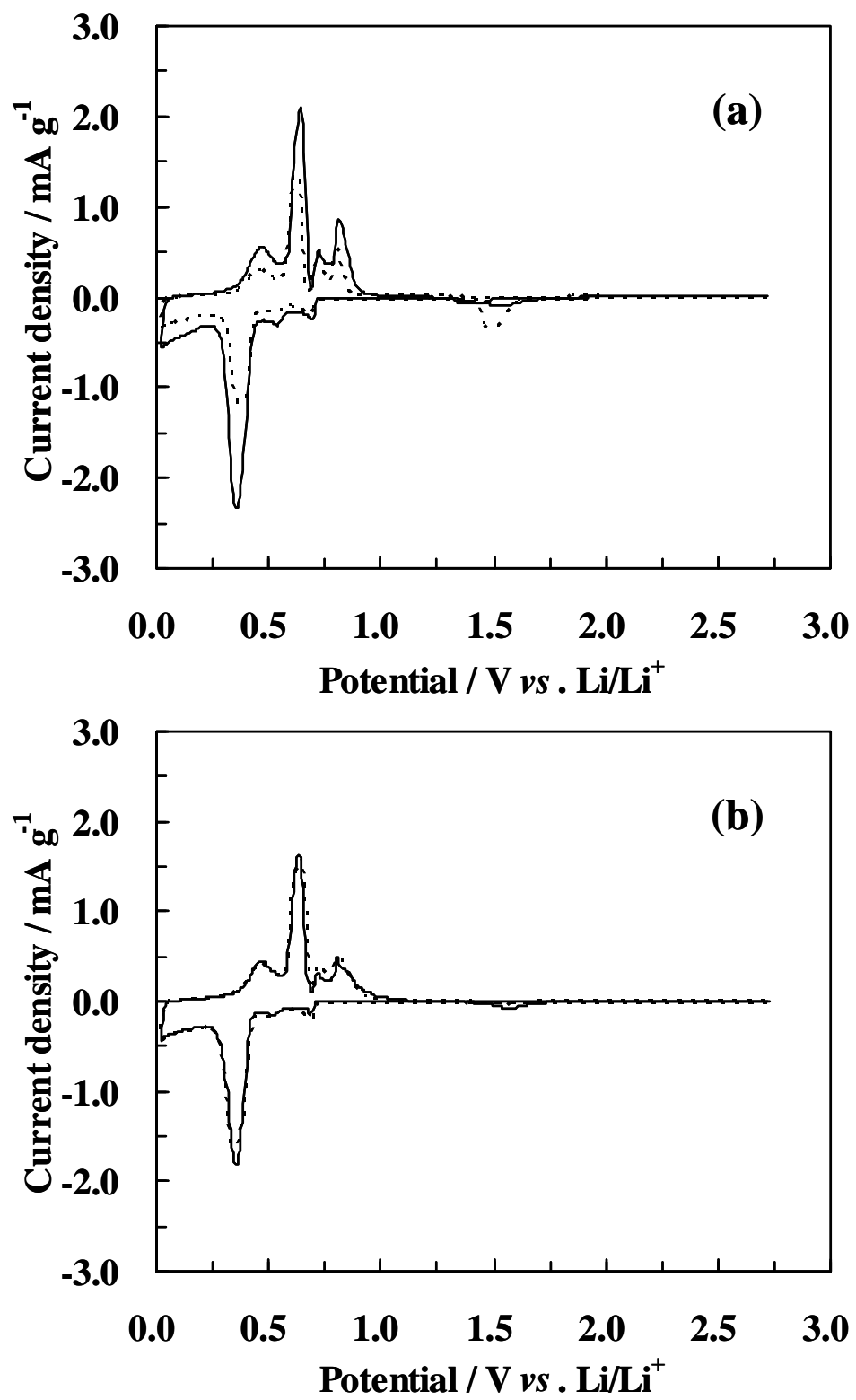

Fig. 2. 

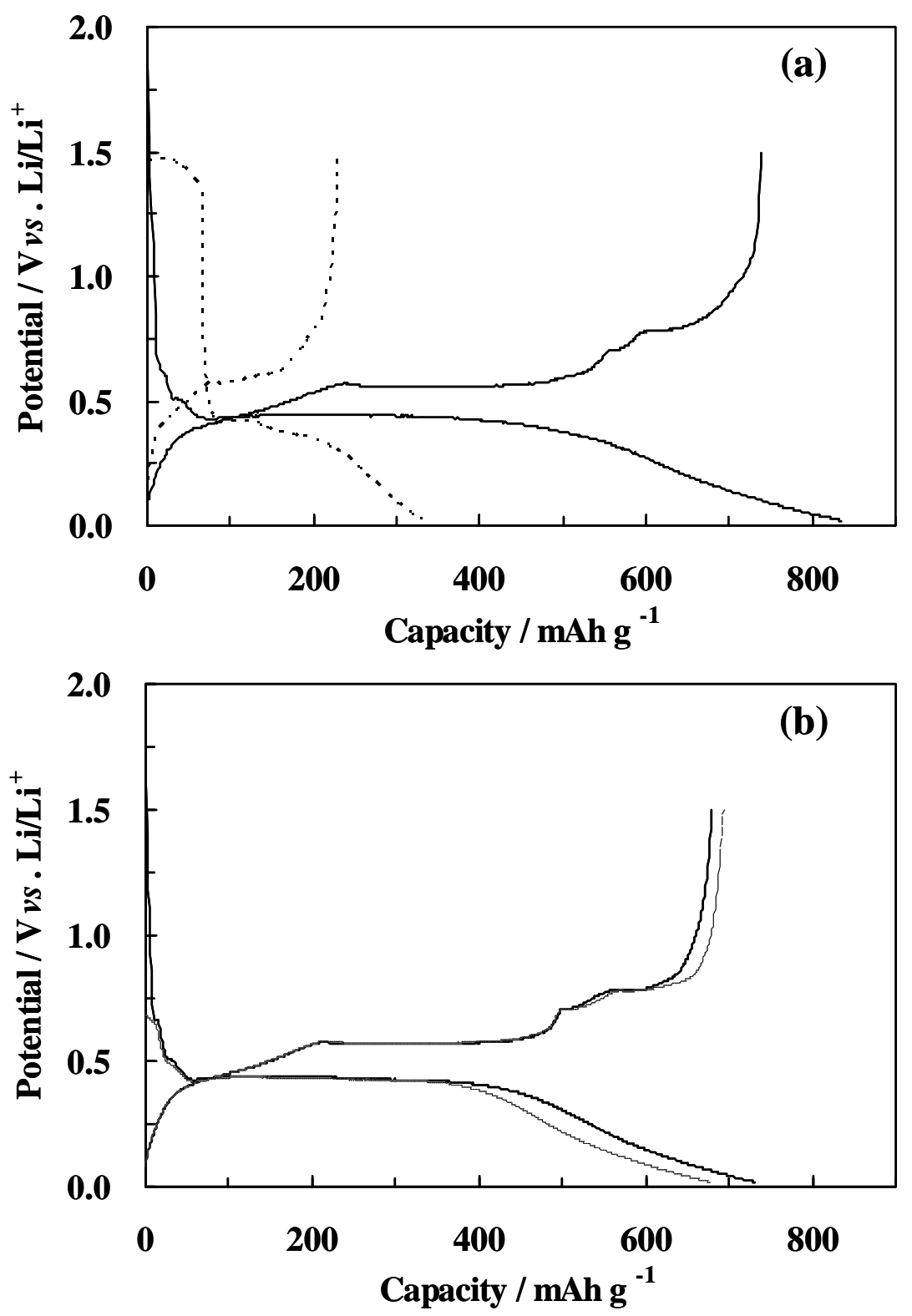

Fig. 3. 
(a)

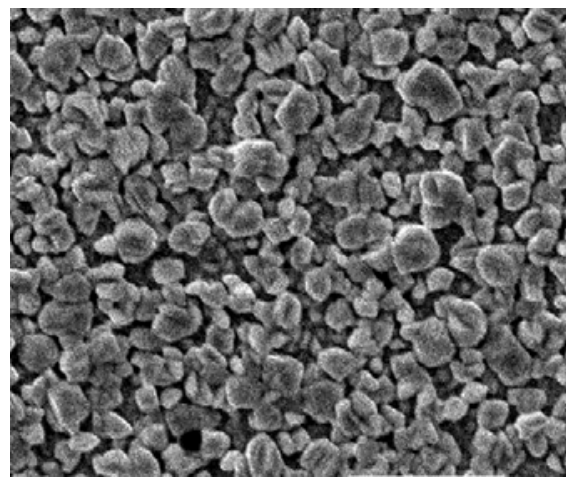

(b)

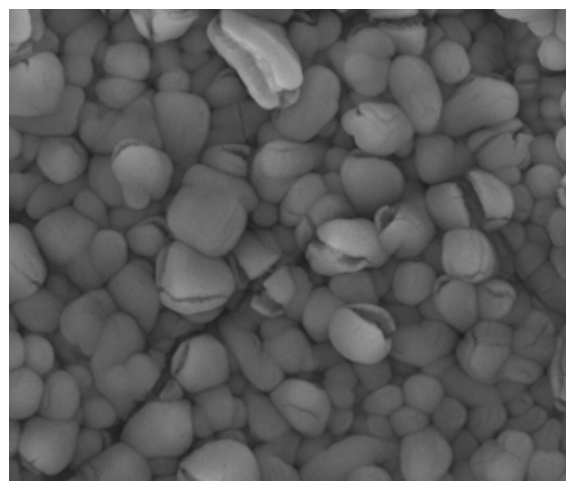

(c)

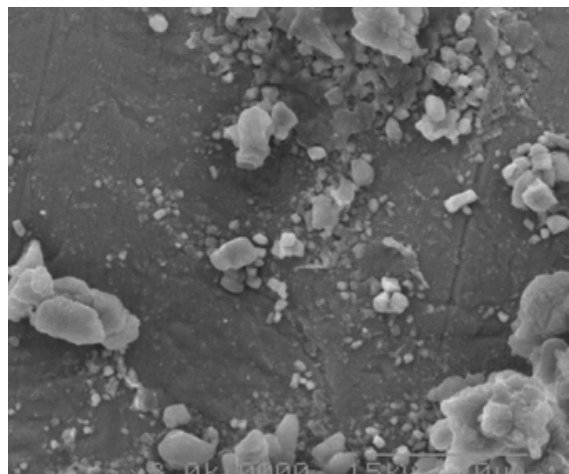

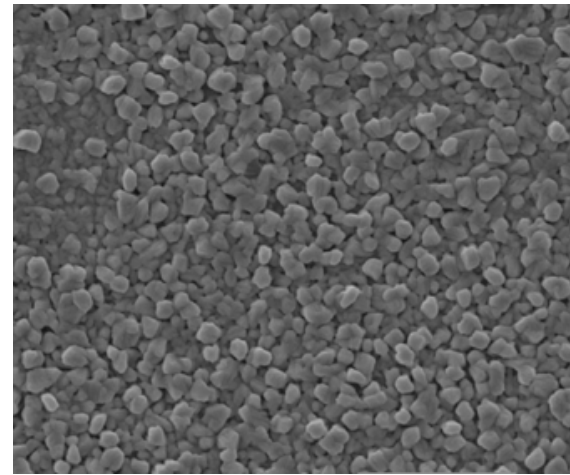

(d)

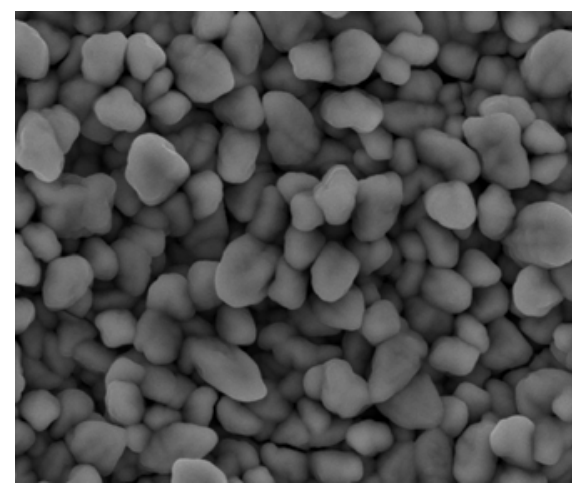

(e)

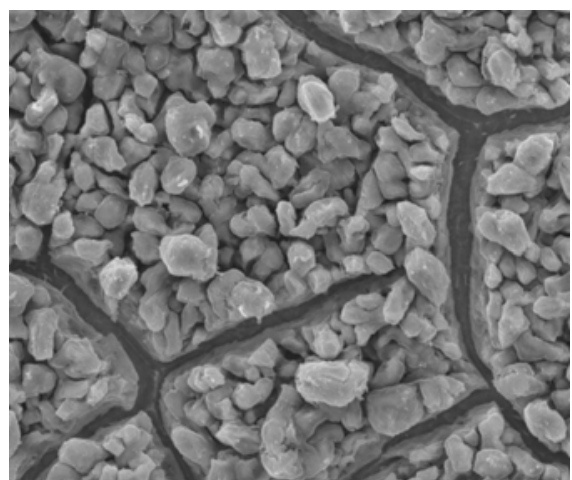

(f)

Fig. 4. 
Constant current method

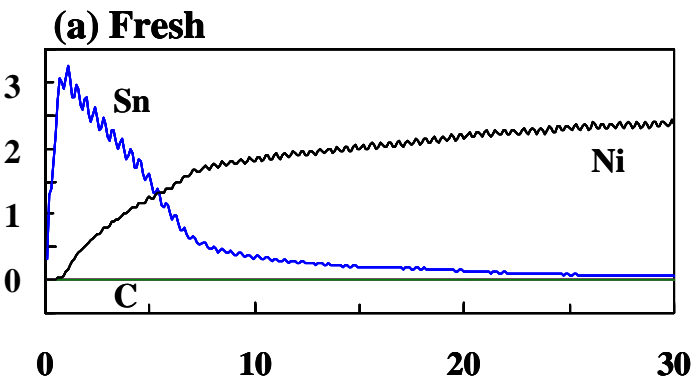

(b) After 1st charge

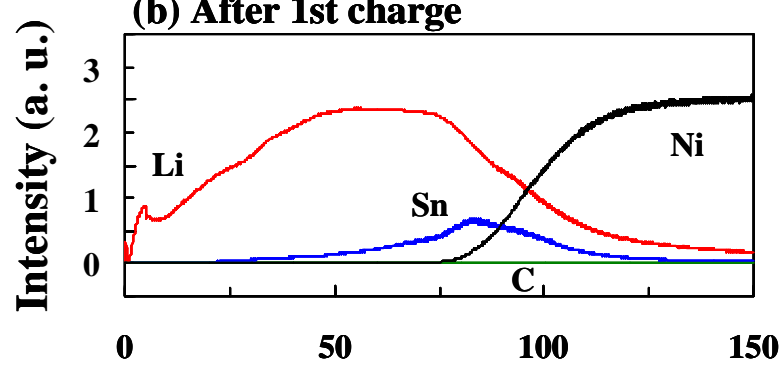

(c) After 1st discharge

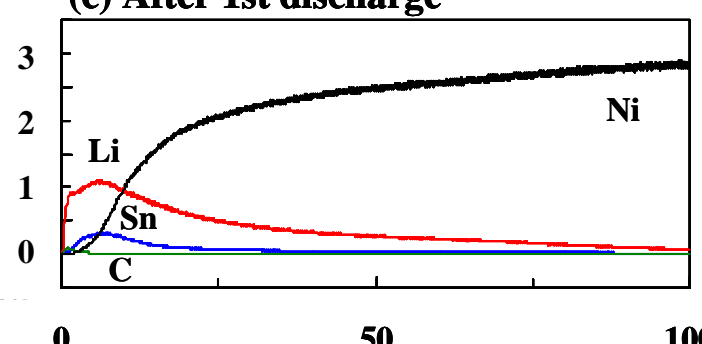

Sputtering time (s)
Pulse method

(d) Fresh

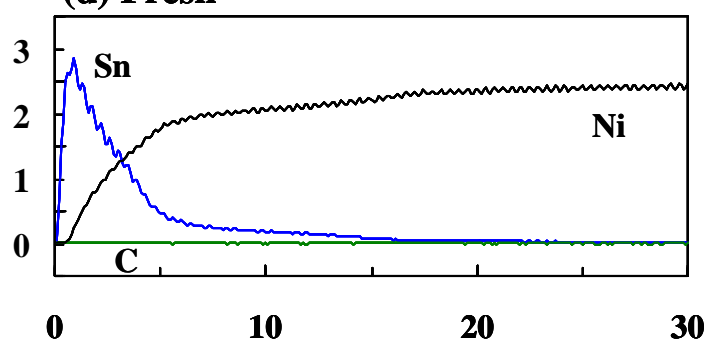

(e) After 1st charge

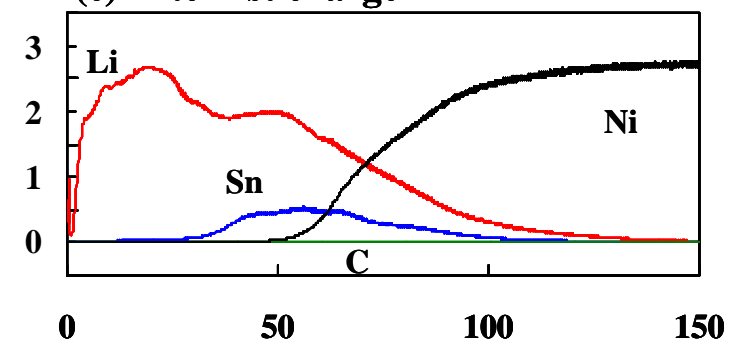

(f) After 1st discharge

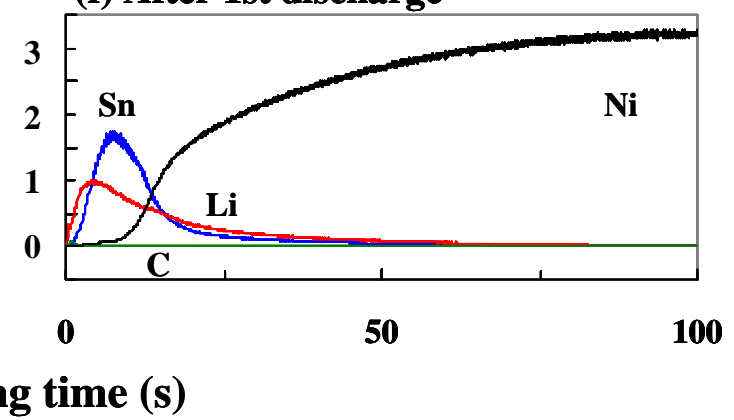

Fig. 5. 


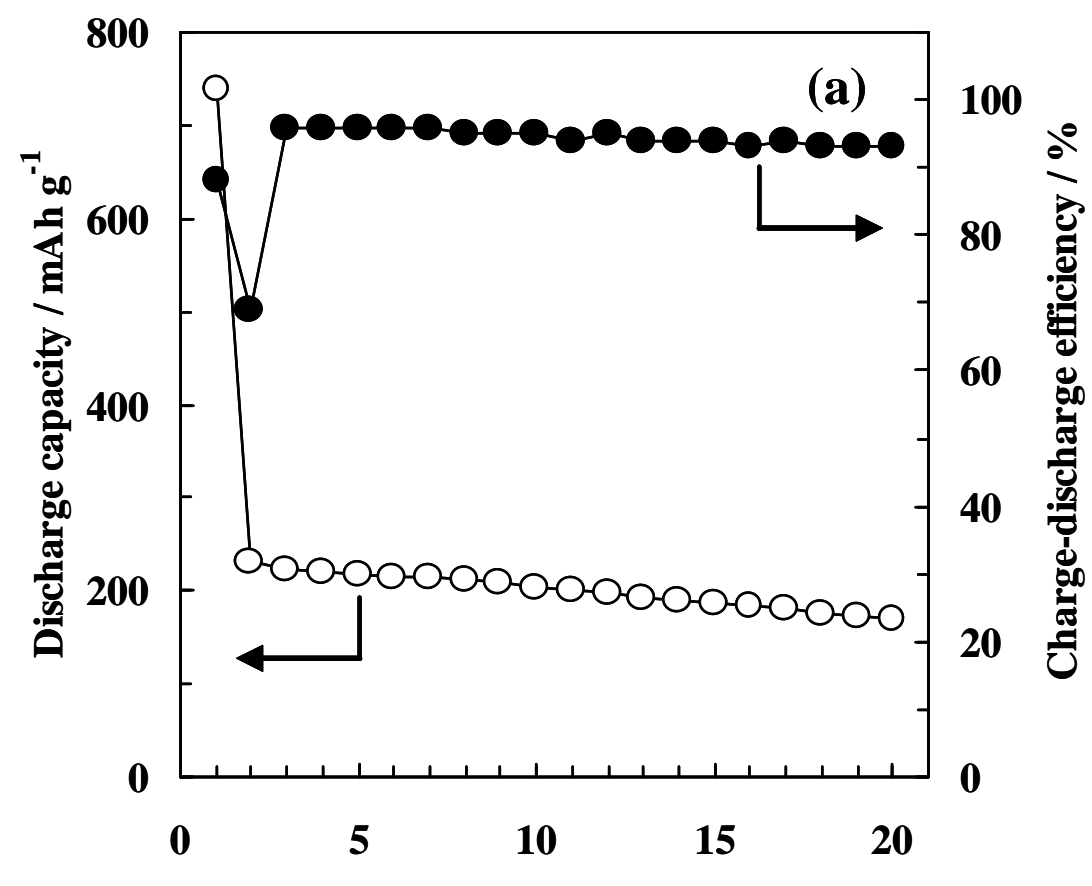

Cycle number

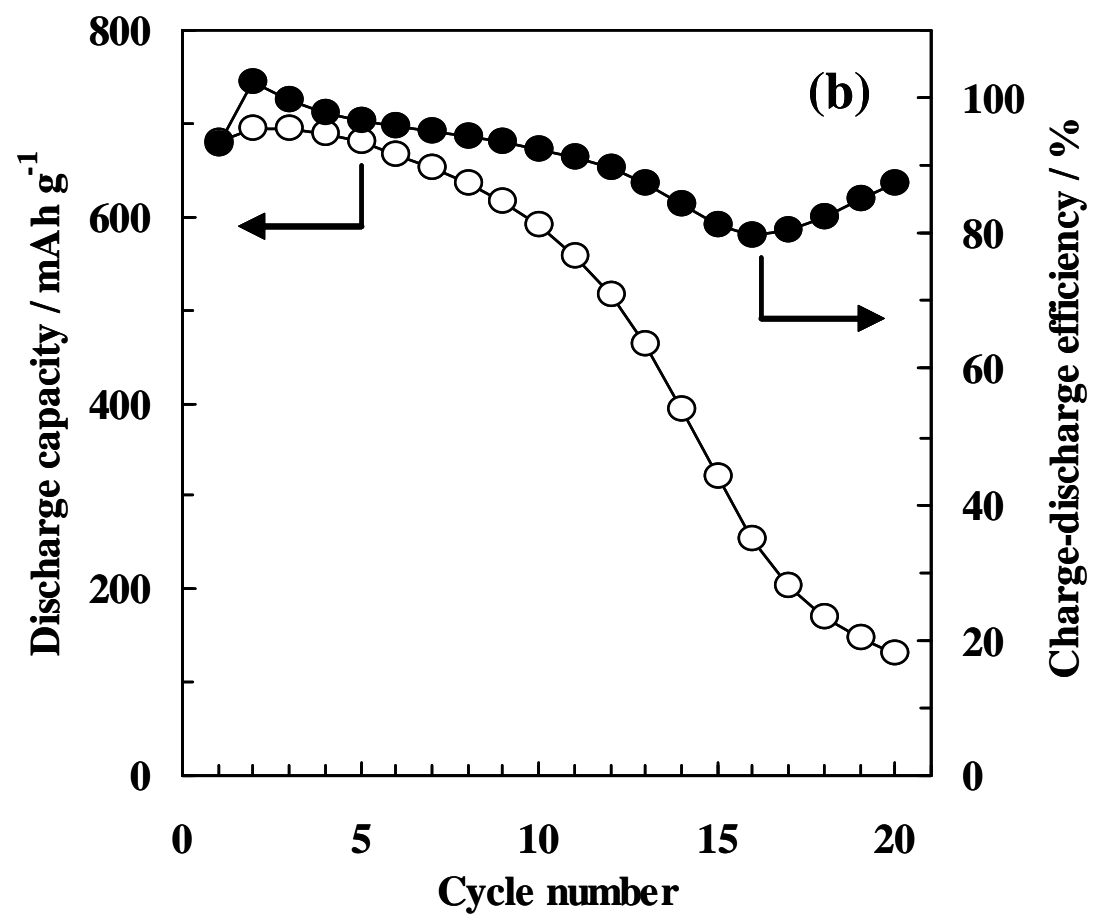

Fig. 6. 
Table 1

\begin{tabular}{cc}
\hline Components & Concentration $\left(\mathrm{mol} \mathrm{dm}^{-3}\right)$ \\
\hline $\mathrm{SnSO}_{4}$ & 0.14 \\
$\mathrm{H}_{2} \mathrm{SO}_{4}$ & 0.98 \\
Gelatin & $1.0 \times 10^{-7}$ \\
\hline
\end{tabular}

